\title{
THE ROLE OF REGULATORY DEFINITIONS
}

Think about the word “woman.” What does it mean? In the Merriam-Webster Dictionary the first definition listed for "woman" is "An adult female person." While this is a perfectly reasonable definition, the point I want to make initially is that if English is your first language, it is highly unlikely that you learned how to use the word "woman" by looking up its dictionary definition. More likely, you have no memory of learning the word, though obviously at some point you did.

Learning a word like "woman"- - a noun that refers to a category of peopletypically involves witnessing the word used by one's parents or acquaintances to refer to what are described as prototypical exemplars. That is, we learn categorydenoting words by seeing or hearing more experienced language-users employ the word with respect to clear examples. As we see or hear the word used to refer to examples, we acquire what are called "learned similarities" among them such that we can successfully generalize from those examples to use the word correctly. When we use the word incorrectly as a child, generally someone corrects us so we learn what does or does not count as a woman.

In fact, most of our vocabulary is learned without ever needing to refer to a dictionary. History illustrates the fact that languages can grow and flourish without collecting formal definitions into a dictionary. After all, the first dictionary of English was Cawdrey's Table Alphabetical in 1604, after William Shakespeare had written such masterpieces as Hamlet and Romeo and Juliet. Furthermore, scholars who study how children learn their first language document that formal dictionary definitions are rarely part of young children's language learning process. Learning to define a word, especially with the classic Aristotelian form ("An X is [a kind of] class name that has such-and-such attributes"), is an advanced linguistic skill developed through "time, practice, and exposure" (Gandía 2016, 4). ${ }^{1}$

Dictionary definitions represent the publisher's account of how words are most commonly used by a linguistic community. Dictionaries provide a descriptive 
account of definitions commonly referred to as lexical definitions. Such definitions obviously change to reflect new language use. In November 2020, for example, Oxford dictionaries updated their account of the word "woman" to correct outdated and sexist usage (Zdanowicz 2020).

A definitional "gap" occurs when someone hears or reads a word they don't recognize and need to look up the definition, such as someone hearing reference to a "shingle" haircut or hearing someone describe a political belief as "antediluvian." Such gaps are easy to fill under most circumstances. Even if several definitions of the same word are listed in a dictionary, an experienced language user normally can consider the context in which the word appears and correctly identify the relevant definition.

Even if children do not learn the meaning of most words by reference to a dictionary, dictionary definitions nonetheless serve a valuable archival function of identifying the most common uses of the words of a given language. They serve as a sort of collective memory to fill in the gap when we read or hear a word with which we are unfamiliar. Dictionaries are descriptive in the sense that they provide the predominant meaning of words, but also prescriptive in the sense that they convey what is taken as the "correct" usage and hence implies how we ought to use words.

Certain definitions describe a category of objects or actions that are considered important only or primarily within highly specific contexts to a particular group of language-users. Thus, in addition to conventional dictionaries, there are dictionaries that are designed for specialized language-users, such as legal dictionaries for the field of law and medical dictionaries for health care professionals. The larger and more complex a society becomes, the greater the need for such resources as specialized dictionaries to ensure that specialists talk the same talk, so to speak.

In this book, I am interested in a specific category of definitions that is a subset of what are known as stipulative definitions. A stipulative definition of a word does not depend on prior usage (though it may be informed by it); rather, a group of language-users agree that in a given context, the word $\mathrm{X}$ has a specified and agreed-upon meaning. For example, in poker the word "flush" is defined by Merriam-Webster as "a hand of playing cards all of the same suit," and the word has no necessary relationship to uses of the word "flush" in other contexts, such as plumbing.

The focus of this book is on what can be called regulatory definitions, understood as stipulative definitions that function to regulate some aspect of human behavior.

Regulatory definitions can be found in a wide array of contexts, from recreational games to laws governing matters of life and death. Learning to play a game typically involves learning the rules, and as games grow more sophisticated, such rules often require a set of specific definitions. The 2019 edition of Major League Baseball's Official Baseball Rules includes a section titled "Definitions of Terms" that includes all of the key words found in the rules, from "adjudged" to "wind-up position." Under normal circumstances, the umpires officiating a game have the power to decide what counts as a "balk," "spectator interference," and so forth. 
As I describe in an earlier book titled Defining Reality: Definitions and the Politics of Meaning, the legal definition of "death" changed in the 1970s and 1980s. Prior to the change, the standard definition used to declare a person "dead" was the cessation of cardio-respiratory activities. As technology changed such that patients could have their cardio-respiratory activities maintained with the aid of machines, the standard definition became one of the cessation of brain activities-so-called "brain death." The legal change was important because there were patients who could be considered alive under one definition but dead under another, and indeed there was a case brought against a doctor for murder for harvesting organs for transplant before the patient was considered dead by current law. Under normal circumstances, it is stipulated by law that an authorized medical professional and only an authorized medical professional has the power to pronounce a person dead.

The two examples I just described may seem quite different, but from the perspective of regulatory definitions, they share important elements. First, from the standpoint of linguistic behavior, regulatory definitions advance what I describe as "denotative conformity." That is, learning the definitional rule that "X counts as $\mathrm{Y}$ in context C"' improves the odds that we understand and describe aspects of our reality in a common manner. We want to be able to observe a phenomenon and agree that $\mathrm{X}$ is a $\mathrm{Y}$. We don't always achieve this goal, as anyone who has observed an argument between a baseball manager and an umpire can attest, but the goal of regulatory definitions is that we use language to describe a situation in a predictable and shared manner. Thus, one important goal of regulatory definitions is denotative conformity.

Second, we define words to serve one or more specific purpose and to promote certain values or interests for those involved. To play baseball, one has to know what counts as a balk, a walk, a run, etc., so the purpose of baseball's rules and definitions is to ensure all players know what is going on and how to play the game. In matters of life and death, there are serious consequences to declaring someone dead, from filing criminal charges of murder in some cases to being permitted to harvest organs to transplant in another. We need to know if a particular person counts as alive or dead to meet all sorts of needs and interests-religious, legal, medical, familial, etc.

Groups, organizations, or institutions have various motivations for advancing regulatory definitions. In games, a paramount value is fairness. And because we value life, it is understandable that we want to be very careful not to make mistakes in pronouncing someone dead prematurely. As we will see later in this book, the question of why an organization or institution is defining a word-what values and interests are being served by a particular definition-is crucial.

Third, regulatory definitions are formulated and authorized by recognized organizations or institutions, such as Major League Baseball or a state legislature. Outside of the purview of those organizations or institutions, the rules potentially have no authority. As this book proceeds, there will be ample examples of how one organization or legal jurisdiction may have one set of definitions (of "male" and "female," for example) that are different from another organization or legal 
jurisdiction. Regulatory definitions always depend on the backing of some sort of recognized entity that has been empowered to regulate a particular domain of human activity. Within the relevant contexts, specific individuals typically are empowered by the regulating entities to decide whether $\mathrm{X}$ counts as $\mathrm{Y}$ or not in any given instance, from an umpire declaring a balk to a medical professional declaring a patient dead.

I argue in this book that - in some contexts-definitions of female and male, women and men, should be treated as regulatory definitions crafted to further social and personal purposes, needs, and interests. They are formulated for the purpose of "determining gender" in specific contexts that are typically segregated by sex (Westbrook \& Schilt 2014). ${ }^{3}$ For the foreseeable future, it is neither necessary nor possible to devise a "one size fits all" definition that will meet all our needs at all times and in all contexts. This will strike some as counter-intuitive, because most of us grow up believing that one's identity as a man or woman is something stable, enduring, and "given" at birth. As we will see, as we move into the third decade of the 21 st century, the situation is more complicated than that.

We have many "social selves," as William James put it (1981, 294); some of those selves are recognized and acknowledged by institutions while others may be relevant only in informal social settings. The point with which I want to end this chapter is that the practice of having regulatory definitions that pertain to our personal identity is not new or unique to defining sex and gender. Each of us, as individuals, have many qualities and attributes that are used to define us in various social contexts. I am an educated, white, cisgender male well over the age of 21 who is a resident of the Commonwealth of Massachusetts. The attribute of my age is irrelevant in some contexts and highly salient in others. My age "entitles" me to certain privileges afforded by governmental agencies or institutions, such as the legal right to buy alcohol, to vote, and to obtain a driver's license. My eligibility for certain institutional benefits that are dependent on age, such as Social Security retirement and Medicare benefits, also is regulated by law. So, age is an identityattribute that is sometimes used to regulate aspects of human behavior and other times is irrelevant.

My status as a white cisgender male is supposed to be irrelevant to most institutional regulations, but I am not so naïve as to deny the unearned privileges historically associated with such an identity. Privilege, including unearned privilege, is negotiated socially, thus various social settings will result in differences in the opportunities or obstacles my social self will encounter. Since I present as a male, for example, my male-identity is accorded privilege in some settings (such as walking down the street at night relatively free of fear of abuse or assault) and disapproval or worse in others (such as in a battered women's shelter, a cloistered convent, or a women-only train car). ${ }^{4}$

One's sex and gender identity is irrelevant in some contexts and highly salient in others. The contexts in which sex and gender identity are subject to specific regulatory definitions adjudicated by specific institutions are relatively rare, but that does not make them unimportant. To understand the complexity of defining sex 
and gender in such contexts, the next chapter provides a brief review of how our understanding of them has changed in recent history.

\section{Notes}

1 I develop the point that children learn language without relying on dictionaries at length in Chapter 2 of Schiappa (2003). See also Litowtiz (1977) and Nippold (1988), Chapter 4.

2 After Searle (1995).

3 As Paisley Currah puts it, "The only thing we can say for sure about what sex means is what a particular state actor says it means" (in Fischel 2019, 100).

4 It should be noted that there are many more contexts that exclude women than exclude men, and that two of my examples of women-only spaces are the result of harassment and violence by men. See Chapter 9 . 